\title{
Arterial Supply of Atrioventricular Node and Bundle in Relation to Degree of Stenosis of Coronary Artery among Sudanese Population (Coronary Angiography Study)
}

\author{
Khalid M. Taha1, Abubaker Y. Elamin'2,3,4, Mohammed H. Karrar Alsharif2,5, \\ Deya Eldin A. Mohamed ${ }^{4,6}$ \\ ${ }^{1}$ Anatomy Department, Faculty of Medicine, Karary University, Omdurman, Sudan \\ ${ }^{2}$ Anatomy Department, Faculty of Medicine, University of Science and Technology, Khartoum, Sudan \\ ${ }^{3}$ Emergency Medical Specialtist Department, Al-Ghad International Colleges for Applied Medical Sciences, \\ Al Madinah Al Munawarah, KSA \\ ${ }^{4}$ Anatomy Department, School of Medicine, Ahfad University for Women, Omdurman, Sudan \\ ${ }^{5}$ Anatomy Department, Prince Sattam Bin Abdulaziz University, Al-Kharj, KSA \\ ${ }^{6}$ Department of Medical Imaging, Al-Ghad International College for Applied Medical Sciences, Dammam, KSA \\ Email: dr.anatomy83@yahoo.com
}

Received 15 February 2015; accepted 18 May 2015; published 21 May 2015

Copyright (C) 2015 by authors and Scientific Research Publishing Inc.

This work is licensed under the Creative Commons Attribution International License (CC BY). http://creativecommons.org/licenses/by/4.0/

(c) (i) Open Access

\section{Abstract}

The coronary arteries diseases are one of the most causes of mortality and morbidity worldwide, particularly in the developing countries. Coronary obstructions are generally described by location and severity of stenosis. Manual tracing and measurement of the stenosis vessel in comparison to reference location of stenosis can be helpful to classify whether a lesion is significant or not. The aim of this study is to identify the dominant type of circulation carried out in patients presented in heart institute and associated with degree of stenosis in RCA and LAD artery. Materials and Methods: This was a retrospective study carried out on patients reporting to Heart Institute from June 2013 to August 2013 (311 patients records as a total coverage were collected as sample) whose coronary artery angiography revealed pathology in coronary arteries. Result: The findings were $\mathbf{7 1 . 7 \%}$ right dominant, $23.5 \%$ left dominant and $4.8 \%$ co-dominant; LAD tends to be stricture 
with right dominant circulation type. LAD artery tends to be stenosis at proximal and mid segment while in the RCA tends to be stenosis in mid and distal segments. The right dominant artery is popular type of circulation in Sudanese people reported in Sudan Heart Institute; there is no significance association between gender and arterial type of circulation and also degree stenosis in LAD degree of stenosis in RCA. I observed that the site of stenosis in LAD artery was proximal and mid ( $P$ value $<0.05$ significance association). Conclusion: Patients present at the heart institute are right dominant mostly coming with proximal and middle LAD stenosis unlike RCA which commonly presents with distal and middle stenosis, so the middle segment of coronary artery is stenosis in both situations. There are wild variations in dominance artery in relation to reduction of diameter in deferent ethic group. There are no significant associations between the gender and dominant artery.

\section{Keywords}

Coronary Arteries, RCA, LAD, Stenosis, Angiography, Atrio Ventricular Node

\section{Introduction}

The coronary arteries diseases are one of the most causes of mortality and morbidity worldwide, particularly in the developing countries [1].

With rising disease burden, an in-depth study of anatomy of coronary arteries has become imperative for better understanding of coronary pathophysiology and better management of the coronary heart disease.

The term (coronary) comes from Latin term "corona" meaning "crown". The two main coronary arteries are the left and right coronary arteries. Left coronary artery (LCA) is divided into the left anterior descending artery (LAD) and the circumflex (LCx) branch. LAD supplies blood to the front of the left side of the heart. The circumflex artery supplies blood to the lateral side and back of the heart. The right coronary artery (RCA) is divided into the posterior descending artery (PDA) and acute marginal arteries. It supplies blood to the right ventricle, right atrium, SA node, atrioventricular node and variable portion of the left ventricle [2].

The term right and left "coronary preponderance" or "dominance" was used to show which coronary artery irrigates the heart's diaphragmatic surface, based on the origin of the posterior descending artery [3].

There are many types of classification of coronary circulation: left coronary artery dominance, right coronary artery dominance, and co-dominant [4]. Various terminologies were used such as "right", "mixed" and "left inferior" [5] [6] preferred to use term "dominance" because it is easy to understand. The term "stenosis" means "a narrowing of a canal or orifice" [7].

The diameter of the normal epicardial coronary artery, prior to its branching and entering the myocardium (where it is no longer susceptible to atherosclerosis) is usually $2-3 \mathrm{~mm}$ [8]. Coronary obstructions are generally described by location and severity of stenosis. In clinical practice, lesion severity is often estimated using axial source images, oblique multi-polar reformations and maximum intensity projection. In case of borderline lesions, manual tracing and measurement of vessels in comparison to location of stenosis can be helpful to classify the lesion significance [3].

Thus the type of circulation has clinical significant finding in ECG at ST segment elevation myocardial infarction. The study of coronary stenosis and dominance would help both surgeon and angiographer radiologist in better dealing with coronary artery disease.

Knowledge of coronary artery variations and stenosis is one of the most important in planning, conducting treatment and in interpretation of findings of the cardiovascular diseases.

The present study is undertaken to determine the pattern of coronary artery dominance in patients presenting in Sudan Heart Institute and documentation of its association with degree of stenosis of LAD, RCA and the site of stenosis.

Different authors wrote about the type of circulation of the coronary artery as in Table 1.

Table 1 shows types of circulation according to cadaveric based studies. 
Table 1. Authors wrote about the type of circulation of the coronary artery.

\begin{tabular}{cccc}
\hline Authors (reference) & \multicolumn{2}{c}{ Type of coronary circulation } \\
& Right dominance & Left dominance & Co-dominance (balanced) \\
\hline Schlesinger [3] & $48 \%$ & $18 \%$ & $34 \%$ \\
Ortale et al. [9] & $62.5 \%$ & $12.5 \%$ & $25 \%$ \\
Fuster et al. [10] & $70 \%$ & $10 \%$ & $20 \%$ \\
Eren et al. [11] & $70 \%$ & $12.5 \%$ & $17.5 \%$ \\
Farahani et al. [12] & $84.2 \%$ & $10.9 \%$ & $3 \%$ \\
Kronzon et al. [13] & $87 \%$ & $10 \%$ & $35 \%$ \\
Mac Alpin [14] & $55 \%$ & $9 \%$ & $30 \%$ \\
Bergman et al. [15] & $50 \%$ & $20 \%$ & $36 \%$ \\
Vasko [16] & $48 \%$ & $16 \%$ & $20 \%$ \\
Franch [17] & $70 \%$ & $10 \%$ & $12.6 \%$ \\
Chaudhry [18] & $75.73 \%$ & $11.65 \%$ & $12 \%$ \\
Murphy et al. [19] & $79 \%$ & $9 \%$ & $20 \%$ \\
\hline Utchins et al. [20] & $70 \%$ & $10 \%$ & $3 \%$ \\
\hline
\end{tabular}

\section{Materials and Methods}

This was a retrospective study carried out on 311 patients reporting to Sudan Heart Institute from July 2013 to August 2013 whose coronary artery angiography revealed pathology in coronary arteries. Sudanese patients' residencies with stenosis in coronary artery angiography were included in this study.

Patient with congenital malformation in heart were excluded from this study.

Sudan heart institute is one of the most specific clinics concerning heart care health; it consists of many departments like cardiac surgery, cardiac medicine and interventional cardiac departments.

There are most sophisticated equipment's found in interventional cardiology department never seen whole part of country.

Data collected about each patient included, age, gender, coronary artery stenosis, and site of stenosis and the dominance of the heart. The data was collected by a check list from patient records.

The data were analyzed by using SPSS (statistical packages for social science) version (17.2) and the (P value $<0.05$ ) was considered as statistically significance.

The ethical issues was approved from ethical committee, anther inform consent given to head manager of Sudan heart institute to allow me conduct such kind of study in department of interventional catheterization lab.

The sample size was 311 calculated by using statistic calculation named EPI info version 11.02.

\section{Results}

The present study was performed on 311 patients underwent coronary angiography in Sudan heart institute. Among them male were 187 (60.1\%) and female were 124 (39.9\%) mean age $57.65 \pm 24.32$. Out of 311 patients heart (128 male - 95 female) of right dominance (Figure 1), 49 male - 24 female of left dominance shown in Figure 2, 10 male - 5 female of co-dominance shown in Figure 3 type of circulation. The percentages 71.7\% right dominance, $23.5 \%$ left dominance $4.8 \%$ co-dominance were tabulated in Table 2.

The right dominance circulation type was more frequent in Sudanese patient presenting in Sudan heart institute; this finding is in conformity with that in published literature [21].

In south India $86.25 \%$ was right dominance, $11.25 \%$ left dominance and co-dominance or (balanced) $2.55 \%$ [22], in the study done in Brazil injection of colored acrylic resin in 25 hearts (72\%) was right dominance, Left dominance occurred in (20\%), co-dominance circulation was observed in (8\%) [23]. also postmortem study of dissecting human hearts of Bangladeshi people the right dominance (91.4\%), left (87.5\%), co-dominance 


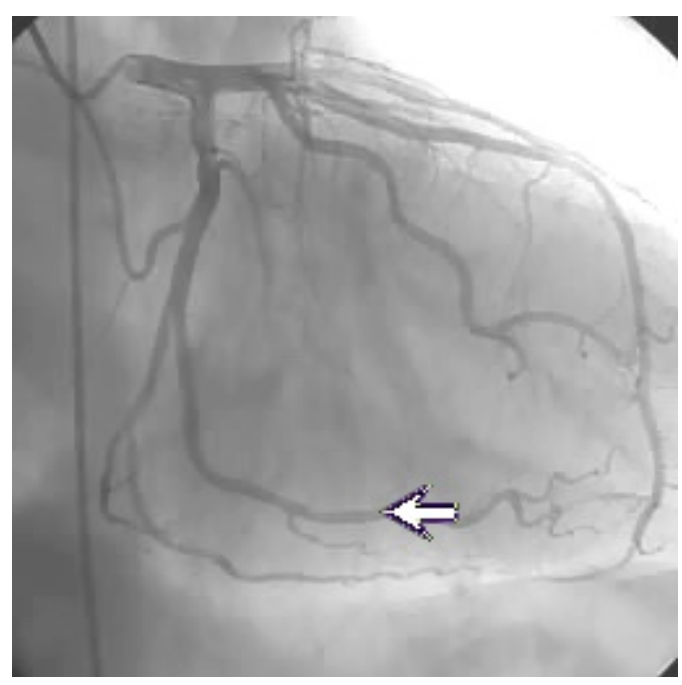

Figure 1. Right coronary dominant depend on origin of PDA.

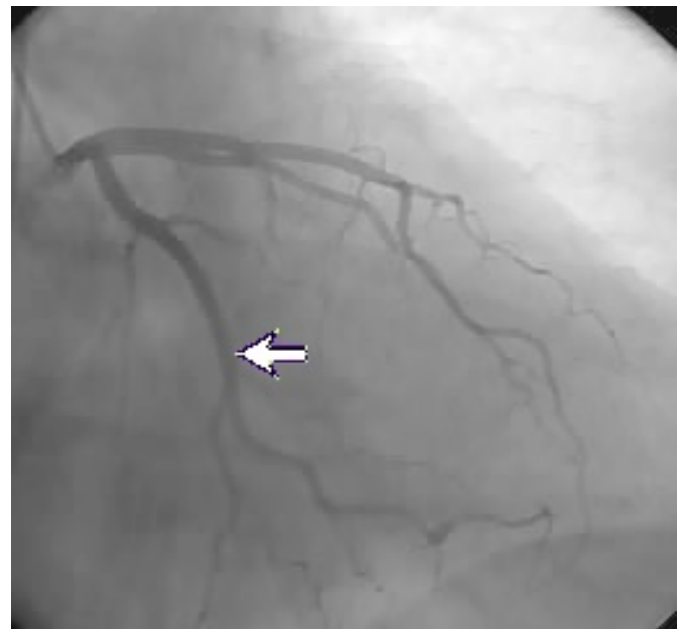

Figure 2. Left coronary dominant depend on origin of PDA.

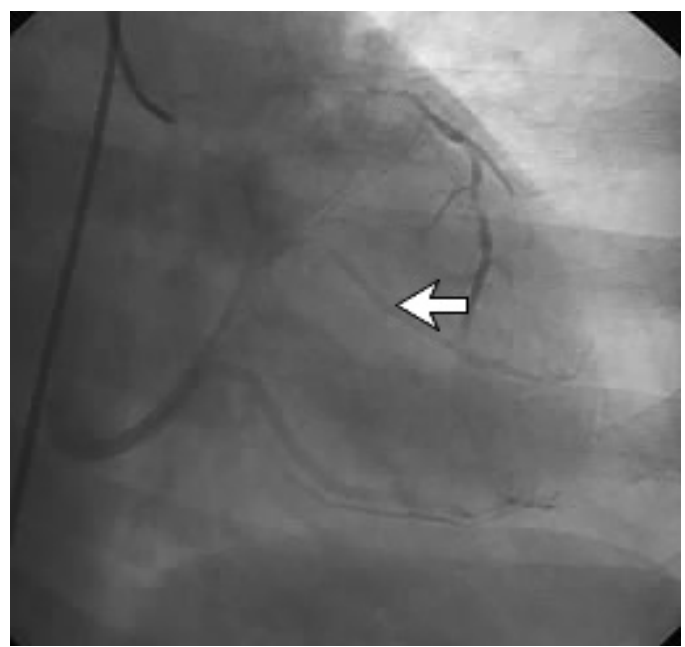

Figure 3. Co-dominant cierculation due to origin of PDA from both coronary arteries. 
(85.7\%) [24].

In this study the frequent LAD artery stenosis was $21.2 \%$ in comparing with RCA $11.3 \%$ the degree of stenosis was severe $(>70 \%-<90 \%)$ in conformity with that reported in published literature, the LAD stenosis was $57 \%$ out of total 54 patients [25] (Graph 1, Graph 2).

In contrast study done in china the RCA was $57.9 \%$ from total 95 patients more affected rather than LAD which was $42.1 \%$ [26], other study done in USA finding the RCA 60\% severe stenosis more than LAD 40\% [27] (Figure 4).

In present study the site of stenosis was more frequent in proximal and mid of LAD artery $25.3 \%$ and $30.5 \%$ respectively comparing to RCA it was $13.2 \%$ in mid and $9.0 \%$ in distal segment in conformity with that reported article [28].

In this study the proximal part of LAD artery was severe stenosis ( $>70 \%-<90 \%) 37 \%$, and totally occluded (100\%) $36.2 \%$ in conformity with that reported in published literature $82.5 \%$ in proximal part of LAD $17.5 \%$ totally occlude [29] (Figure 5).

Study done in Graz city reveals that the proximal part of LAD artery was most affected by stenosis [3] [30] (Table 3, Table 4).

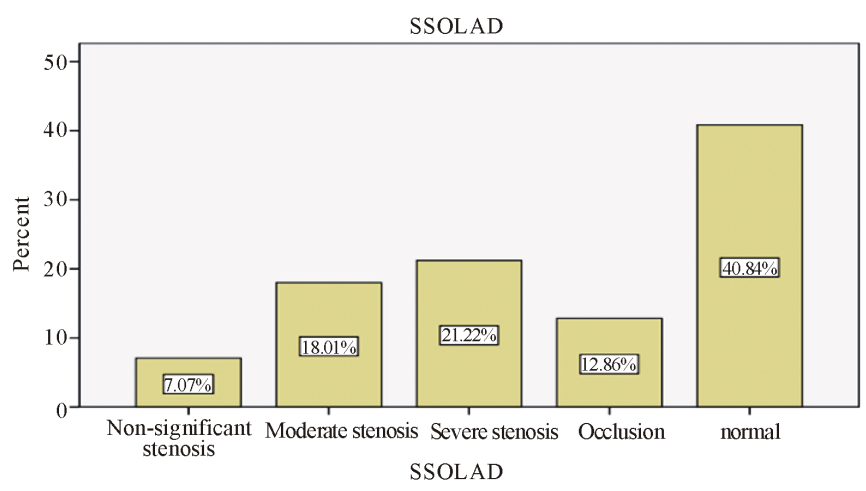

Graph 1 . The frequent of severity degree of stenosis in LAD artery (SSOLAD).

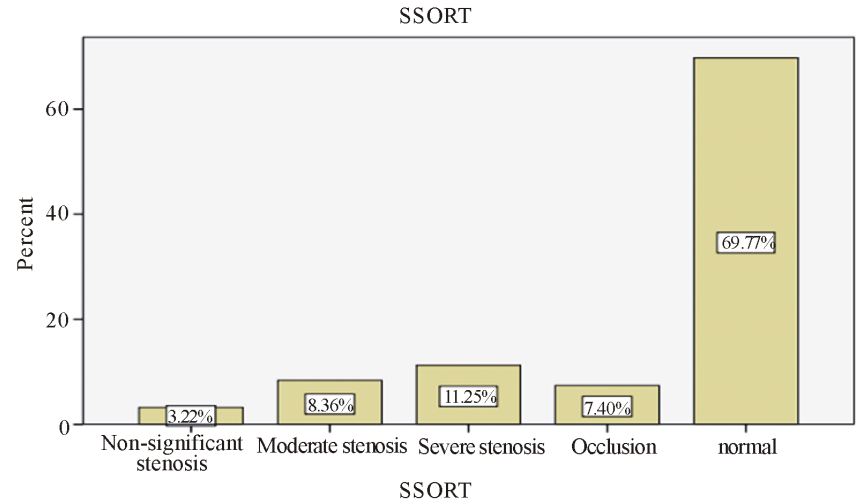

Graph 2. The frequent of severity degree of stenosis in right coronary artery (SSORT).

Table 2. Pattern of coronary arterial distribution.

\begin{tabular}{cccc}
\hline & Frequency & Percent\% \\
\hline \multirow{2}{*}{ Ralid } & Left dominant & $73(49$ male -24 female $)$ & 71.7 \\
& Co-dominant & $15(10$ male -5 female $)$ & 23.5 \\
& Total & 311 & 100.0 \\
\hline
\end{tabular}




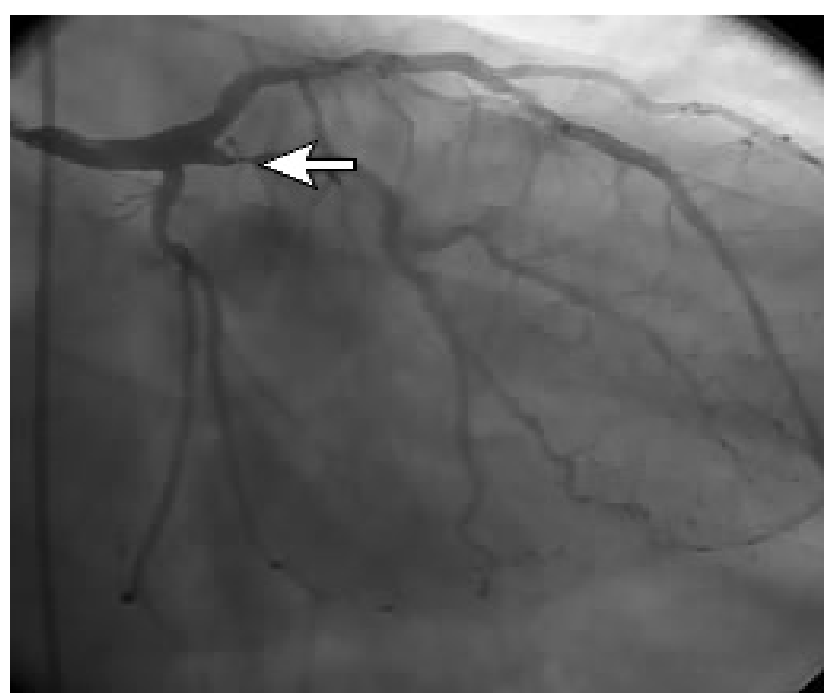

Figure 4. Proximal position of LAD artery stenosis.

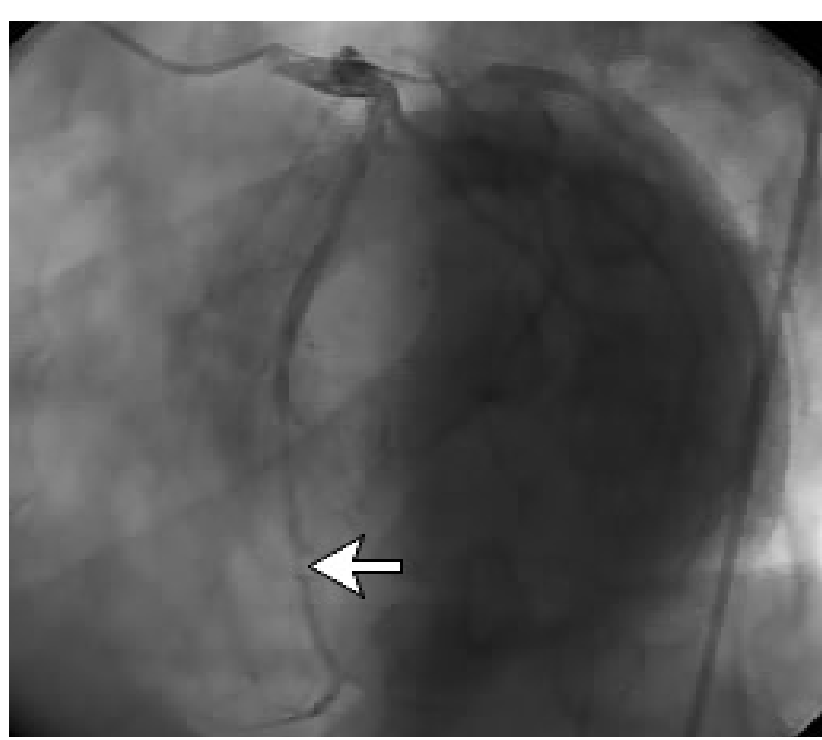

Figure 5. Distal position of RCA stenosis.

Table 3. Frequency site stenosis of left anterior descending artery.

\begin{tabular}{|c|c|c|c|c|c|}
\hline & & Frequency & Percent & Valid percent & Cumulative percent \\
\hline & Proximal & 78 & 25.1 & 25.3 & 25.3 \\
\hline \multirow{3}{*}{ Valid } & Middle & 94 & 30.2 & 30.5 & 55.8 \\
\hline & Distal & 19 & 6.1 & 6.2 & 62.0 \\
\hline & None & 117 & 37.6 & 38.0 & 100.0 \\
\hline \multirow{3}{*}{ Missing } & Total & 308 & 99.0 & 100.0 & \\
\hline & System & 3 & 1.0 & & \\
\hline & & 311 & 100.0 & & \\
\hline
\end{tabular}


Table 4. Frequency site of stenosis in right coronary artery.

\begin{tabular}{|c|c|c|c|c|c|}
\hline & & Frequency & Percent & Valid percent & Cumulative percent \\
\hline \multirow{5}{*}{ Valid } & Proximal & 22 & 7.1 & 7.1 & 7.1 \\
\hline & Middle & 41 & 13.2 & 13.2 & 20.3 \\
\hline & Distal & 28 & 9.0 & 9.0 & 29.3 \\
\hline & None & 220 & 70.7 & 70.7 & 100.0 \\
\hline & Total & 311 & 100.0 & 100.0 & \\
\hline
\end{tabular}

Table 5. Distribution type of circulation in relation to the degree of stenosis in RCA.

\begin{tabular}{|c|c|c|c|c|c|c|c|}
\hline & & \multicolumn{5}{|c|}{ SSORT } & \multirow{2}{*}{ Total } \\
\hline & & $\begin{array}{l}\text { Non-significant } \\
\text { stenosis }\end{array}$ & Moderate stenosis & Severe stenosis & Occlusion & Normal & \\
\hline \multirow{3}{*}{ Arterial dominance } & Right dominant & 6 & 23 & 26 & 18 & 150 & 223 \\
\hline & Left dominant & 2 & 1 & 7 & 5 & 58 & 73 \\
\hline & Co-dominant & 2 & 2 & 2 & 0 & 9 & 15 \\
\hline Total & & 10 & 26 & 35 & 23 & 217 & 311 \\
\hline
\end{tabular}

Table 6. Distribution type of circulation in relation to the degree of stenosis in LAD artery.

\begin{tabular}{|c|c|c|c|c|c|c|c|}
\hline & & \multicolumn{5}{|c|}{ SSOLAD } & \multirow{2}{*}{ Total } \\
\hline & & $\begin{array}{l}\text { Non-significant } \\
\text { stenosis }\end{array}$ & Moderate stenosis & Severe stenosis & Occlusion & Normal & \\
\hline \multirow{3}{*}{ Arterial dominance } & Right dominant & 15 & 37 & 47 & 29 & 95 & 223 \\
\hline & Left dominant & 5 & 16 & 14 & 11 & 27 & 73 \\
\hline & Co-dominant & 2 & 3 & 5 & 0 & 5 & 15 \\
\hline Total & & 22 & 56 & 66 & 40 & 127 & 311 \\
\hline
\end{tabular}

The right dominant artery has more tendencies toward to become stenosis than other type of circulation this finding was in conformity with that published in literature [31] (Table 5, Table 6).

\section{Discussion}

This study reveals that the right coronary artery is the dominant type of circulation compared to the left coronary artery, the incidence of stenosis increased with this type of circulation due to lack of anastomosis inter connection between LAD and RCA when the type of circulation was right, and also this type of circulation increases frequently in male more than female. The LAD artery tends to be stenosis more frequent than RCA, due to shortly origin from left coronary artery and because it tortiousness when it descend downward, also I observed that the site of stenosis in LAD artery was proximal and mid ( $\mathrm{P}$ value $<0.05$ significance association) as in confirm in published article [32] while in RCA tend to become in mid and distal segment, this due to acute angle between the left ventricular surface and the proximal part of the vessel, while in right coronary artery is wide in proximal but becomes narrow when it passes close to lower border.

In this study there is no significance association between gender and arterial type of circulation and also degree stenosis in LAD degree of stenosis in [32]. Disagreement with that reported in literature. 


\section{Conclusions}

From this study the type coronary circulation in Sudanese patients presented in Sudan Heart Institute is right dominant artery with most sites of stenosis in proximal and middle for LAD artery, and distal and middle in RCA, so the middle segment of coronary artery is stenosis in both situations. I can conclude that there are wild variations in dominance artery in related reduction of diameter in deferent ethic group.

There are no significant associations between the gender and dominant artery.

There are many limitations in this study: the time of data collection was too short; MSCT was not used to detect accurate caliber of the vessels from this results; and all the data collected were just patients' records, so we cannot generalize this result to all Sudanese population.

\section{Recommendations}

We recommend that future studies should investigate diameter of coronary artery using 64 slice MSCT scan to determine the tapering of the vessel from the origin to the termination of the arteries and also to determine the dominance artery in relation to deferent ethnic groups.

\section{References}

[1] Mandal, S., Saha, J.B., Mandal, S.C., Bhattacharya, R.N., Chakraborty, M. and Pal, P.P. (2009) Prevalence of Ischemic Heart Disease among Urban Population of Siliguri, West Bengal. Indian Journal of Community Medicine: Official Publication of Indian Association of Preventive \& Social Medicine, 34, 19-23. http://dx.doi.org/10.4103/0970-0218.44518

[2] Libby, P., Bonow, R.O., Mann, D.L., Zipes, D.P. and Libby, P. (2008) Braunwald's Heart Disease: A Textbook of Cardiovascular Medicine. 8th Edition, Saunders, Philadelphia, 478 p.

[3] Schlesinger, J.M. (1940) Relation of Anatomic Pattern to Pathologic Conditions of the Coronary Arteries. American Heart Journal, 20, 252. http://dx.doi.org/10.1016/S0002-8703(40)90791-8

[4] Gawlikowska-Sroka, A., Miklaszewska, D. and Czerwinski, F. (2010) Analysis of the Influence of Heart Size and Gender on Coronary Circulation Type. Folia Morphologica, 69, 35-41.

[5] Vieweg, W.V., Alpert, J.S. and Hagan, A.D. (1975) Origin of the Sinoatrial Node and Atrioventricular Node Arteries in Right, Mixed, and Left Inferioremphasis Systems. Catheterization and Cardiovascular Diagnosis, 1, 361-373. http://dx.doi.org/10.1002/ccd.1810010405

[6] Standring, S. (2008) Gray’s Anatomy: The Anatomical Basis of Clinical Practice. 40th Edition, Elsevier, St. Louis Sydney, 1576 p.

[7] Sadler, T.W. (2011) Langman’s Medical Embryology. Lippincott Williams and Wilkins, Philadelphia, 384 p.

[8] Factors, S.M., Lamberti-Abadi, M.A. and Abadi, J. (2001) Handbook of Pathology and Pathophysiology of Cardiovascular Disease (Developments in Cardiovascular Medicine). 8th Edition, Kluwer Academic Publisher, Norwell, 312 p.

[9] Ortale, J.R., Keiralla, L.C. and Sacilotto, L. (2004) The Posterior Ventricular Branches of the Coronary Arteries in the Human Heart. Arquivos Brasileiros de Cardiologia, 82, 468-472.

[10] Fuster, V., Alexander, R.W. and Wellens, H.J.J. (2000) Hurst's the Heart. 10th Edition, McGraw-Hill, Philadelphia, $1080 \mathrm{p}$.

[11] Eren, S., Bayram, E., Fil, F., Koplay, M., Sirvanci, M., Duran, C., et al. (2008) An Investigation of the Association between Coronary Artery Dominance and Coronary Artery Variations with Coronary Arterial Disease by Multidetector Computed Tomographic Coronary Angiography. Journal of Computer Assisted Tomography, 32, 929-933. http://dx.doi.org/10.1097/RCT.0b013e3181593d5b

[12] Vasheghani-Farahani, A., Kassaian, S.E., Yaminisharif, A., Davoodi, G., Salarifar, M., Amirzadegan, A., et al. (2008) The Association between Coronary Arterial Dominancy and Extent of Coronary Artery Disease in Angiography and Paraclinical Studies. Clinical Anatomy, 21, 519-523. http://dx.doi.org/10.1002/ca.20669

[13] Kronzon, I., Deutsch, P. and Glassman, E. (1974) Length of the Left Main Coronary Artery: Its Relation to the Pattern of Coronary Arterial Distribution. The American Journal of Cardiology, 34, 787-789. http://dx.doi.org/10.1016/0002-9149(74)90697-3

[14] MacAlpin, R.N., Abbasi, A.S., Grollman Jr., J.H. and Eber, L. (1973) Human Coronary Artery Size during Life. A Cinearteriographic Study. Radiology, 108, 567-576. http://dx.doi.org/10.1148/108.3.567

[15] Bergman, R.A., Thompson, S.A. and Afifi, A.K. (1988) Compendium of Human Anatomic Variation: Text, Atlas, and 
World Literature. Urban \& Schwarzenberg, Baltimore, 607 p.

[16] Vasko, J.S., Gutelius, J. and Sabiston Jr., D.C. (1961) A Study of Predominance of Human Coronary Arteries Determined by Arteriographic and Perfusion Technics. The American Journal of Cardiology, 8, 379-384. http://dx.doi.org/10.1016/0002-9149(61)90157-6

[17] Cohn, P. and Goldberg, S. (1985) Cardiac Catheterization and Coronary Arteriography. In: Cohn, P.F., Ed., Diagnosis and Therapy of Coronary Artery Disease, Springer, New York, 219-260. http://dx.doi.org/10.1007/978-1-4613-2569-7 9

[18] Chaudhry, M.S. (1965) Some Observation on the Coronary Artery Pattern and Inter-Coronary Anastomoses in Human Hearts. Medicus Karachi, 30, 160-172.

[19] Murphy, E.S., Rosch, J. and Rahimtoola, S.H. (1977) Frequency and Significance of Coronary Arterial Dominance in Isolated Aortic Stenosis. The American Journal of Cardiology, 39, 505-509. http://dx.doi.org/10.1016/S0002-9149(77)80158-6

[20] Hutchins, G.M., Nazarian, I.H. and Bulkley, B.H. (1978) Association of Left Dominant Coronary Arterial System with Congenital Bicuspid Aortic Valve. The American Journal of Cardiology, 42, 57-59. http://dx.doi.org/10.1016/0002-9149(78)90985-2

[21] Mian, F.A., Malik, S.N., Ismail, M., Khan, I.S., Kachlu, A.R., Rehman, M., et al. (2011) Coronary Artery Dominance: What Pattern Exists in Pakistani Population? Annals of Pakistan Institute of Medical Sciences, 7, 3-5.

[22] Kumar, K. (2012) Balanced or Co-Dominance Is an Impossible Coronary Arterial Pattern. Anatomica Karnataka, 6, 38-40.

[23] Abuchaim, D.C.S., Spera, C.A., Faraco, D.L., Ribas Filho, J.M. and Malafaia, O. (2009) Coronary Dominance Patterns in the Human Heart Investigated by Corrosion Casting. Revista Brasileira de Cirurgia Cardiovascular, 24, 514-518.

[24] Hussain, M., Nahar, A. and Ara, S. (2008) The Dominance Pattern of Coronary Artery of Adult Bangladeshi PeopleA Postmortem Morphological Study. Cardiovascular Journal, 1, 21-25.

[25] Segall, G.M., Atwood, J.E., Botvinick, E.H., Dae, M.W. and Lucas, J.R. (1995) Variability of Normal Coronary Anatomy: Implications for the Interpretation of Thallium-SPECT Myocardial Perfusion Images in Single-Vessel Disease. Journal of Nuclear Medicine: Official Publication, Society of Nuclear Medicine, 36, 944-951.

[26] Lu, T.-M., Jou, Y.-L., Chen, Y.-H., Chen, L.-C., Sung, S.-H., Chan, W.-L. and Lin, S.-J. (2011) The Clinical Significance of Right Coronary Artery Stenosis on the Prognosis of Patients with Unprotected Left Main Disease Undergoing Percutaneous Coronary Intervention. Acta Cardiologica Sinica, 27, 14-20.

[27] Bunce, N.H., Reyes, E., Keegan, J., Bunce, C., Davies, S.W., Lorenz, C.H., et al. (2004) Combined Coronary and Perfusion Cardiovascular Magnetic Resonance for the Assessment of Coronary Artery Stenosis. Journal of Cardiovascular Magnetic Resonance: Official Journal of the Society for Cardiovascular Magnetic Resonance, 6, 527-539.

[28] Gensini, G.G. and Kisco, M. (1975) Coronary Arteriography. American Heart Journal, 407, 91.

[29] Proudfit, W.L., Shirey, E.K. and Sones Jr., F.M. (1967) Distribution of Arterial Lesions Demonstrated by Selective Cinecoronary Arteriography. Circulation, 36, 54-62. http://dx.doi.org/10.1161/01.CIR.36.1.54

[30] Wehrschuetz, M., Wehrschuetz, E., Schuchlenz, H. and Schaffler, G. (2010) Accuracy of MSCT Coronary Angiography with 64 Row CT Scanner-Facing the Facts. Clinical Medicine Insights Cardiology, 4, 15-22. http://dx.doi.org/10.4137/CMC.S3864

[31] Gerber, B.L., Coche, E., Pasquet, A., Ketelslegers, E., Vancraeynest, D., Grandin, C., et al. (2005) Coronary Artery Stenosis: Direct Comparison of Four-Section Multi-Detector Row CT and 3D Navigator MR Imaging for DetectionInitial Results. Radiology, 234, 98-108. http://dx.doi.org/10.1148/radiol.2341031325

[32] Kaimkhani, Z.A., Ali, M.M. and Faruqi, A.M. (2005) Pattern of Coronary Arterial Distribution and Its Relation to Coronary Artery Diameter. Journal of Ayub Medical College, Abbottabad: JAMC, 17, 40-43. 